\title{
Measurement of Dissolved ORGaniC CARBON AND NITROGEN IN NATURAL WATERS
}

\author{
By Peter M. Williams ${ }^{\star}$
}

\begin{abstract}
$\mathrm{T}$ HE POTENTIAL IMPACT of elevated dissolved organic carbon (DOC) and nitrogen (DON) concentrations on the biogeochemical cycling of organic matter in the oceans is profound. Yet we are at an impasse in obtaining accurate measurements of DOC and DON. A Workshop in Seattle (15-19 July 1991) was conceived to bring order to the present uncertainties in these measurements and to make explicit recommendations for future analytical protocols and experimentation.
\end{abstract}

\section{Background}

Confirmation and replication of elevated DOC and DON values, as measured by Sugimura and Suzuki (1988) and Suzuki et al. (1985) in the western Pacific Ocean, has proven to be elusive and equivocal in other oceanic regimes. Questions posed by an earlier commentary in Oceanography (Williams and Druffel, 1988) are still largely unanswered.

A "mini" DOC Workshop in November 1987 at the Woods Hole Oceanographic Institution was convened on the basis of widespread circulation of the Sugimura and Suzuki (1988) preprint. At this workshop, Y. Suzuki measured DOC and DON in a selection of seawater samples using his high-temperature catalytic oxidation (HTCO) techniques. The results he obtained were up to $100 \%$ higher than those measured concurrently with several other HTCO analyzers and up to six times those measured by wet combustion (WCO). The general feeling of the participants at this mini workshop was that it should be a relatively straightforward task to fabricate a Suzuki-type

* Written on behalf of, and with the advice of, the DOC/ DON Workshop Steering Committee: J. Hedges (Chair), J. Farrington (Co-Chair), R. Benner, C. Lee, F. Mantoura. Y. Suzuki and P. Williams. Opinions and speculations are solely those of the author.

P. M. Williams, Marine Research Division, Scripps Institution of Oceanography, University of California, San Diego. La Jolla, CA 92093-0218, USA. analyzer (Suzuki-clone) and replicate his results or to obtain comparable results using modifications of commercially available HTCO analyzers. This turned out to be wishful thinking.

A number of investigators, using the SugimuraSuzuki (Sumika Chemical Analysis Service Ltd.) $3 \% \mathrm{Pt} / \mathrm{Al}_{2} \mathrm{O}_{3}$ catalyst or other combustion-tube packings (including $\mathrm{Pt}$ gauze, $\mathrm{Pt}$ on alumina and aluminosilicate substrates, $\mathrm{Co} / \mathrm{CoO}$, quartz chips, and unpacked steel tubes) have found DOC but not DON concentrations higher than those normally measured with WCO techniques. The majority of these HTCO measurements, regardless of the analyzers employed, have given DOC values $10-20 \%$ lower than those found by Sugimura and Suzuki, even when analyzing identical seawater samples. There has been no unequivocal confirmation of the Sugimura/Suzuki values by simultaneous measurements of DOC (or DON) in the same seawater samples by Y. Suzuki and a second analyst using identical instrumentation and catalysis under identical experimental conditions.

Recently, similar DOC values have been measured by Y. Suzuki and others for identical samples using different analyzers. Bauer et al. (1990) using a $\mathrm{Co} / \mathrm{CoO}$ catalyst at $900^{\circ} \mathrm{C}$ (Dohrmann TC-90 analyzer) obtained DOC values nearly identical to those measured by $\mathrm{Y}$. Suzuki in frozen samples from a profile taken in the Sargasso Sea $(0-4500 \mathrm{~m})$. E. Peltzer (Woods Hole Oceanographic Institution) analyzed identical surface and deep samples with Y. Suzuki during the 1989 Joint Global Oceans Flux Study (JGOFS) North Atlantic Bloom Experiment using a pure platinum catalyst at $800^{\circ} \mathrm{C}$ (Ionics Model 555 TC-analyzer). Their deep-water results were comparable, but the WHOI values were significantly lower in the upper $100 \mathrm{~m}$ (E. Peltzer, personal communication). Most recently, S. Fitzwater and J. Martin (Moss Landing Laboratory; see Table 1 and unpublished results) and $Y$. Suzuki analyzed the same frozen samples from the North Atlantic Bloom experi-

\section{Confirmation and}

replication of elevated

DOC and DON values

... has proven to be

elusive and equivo-

cal ... 
Table 1

Background papers and data reports from the workshop.

Alperin, M.J. and C.S. Martens (Data Report). Dissolved organic carbon in marine pore waters. Comparison of three oxidation methods.

Bauer, J.E., M.L. Occelli, P.M. Williams and P.C. McCashin (Background Paper). Heterogeneous catalyst structure and function: review and implications for the analysis of dissolved organic carbon in natural waters.

Benner, R. and M. Strom (Data Report). A critical evaluation of the analytical blank associated with DOC measurements by high-temperature catalytic oxidation.

Fitzwater. S.E. and J.H. Martin (Data Report). Notes on the JGOFS North Atlantic bloom experiment: dissolved organic carbon intercomparison.

Fry, B., S. Saupe, M. Hullar and B.J. Peterson (Data Report). Platinum-catalyzed combustion of DOC in scaled tubes for stable isotopic analysis.

Hansell, D.A. (Data Report). Results and observations from the measurement of DOC and DON in seawater using a high-temperature catalytic oxidation technique.

Hedges, J.I.. B.A. Bergamaschi and R. Benner (Workshop Data Report). Comparative analysis of DOC and DON in natural waters.

Karl, D.M., G. Tien, J. Dore and C.D. Winn (Data Report). Total dissolved nitrogen and phosphorus concentrations at US-JGOFS Station ALOHA: Redfield reconciliation.

Koike, I. and L. Tupas (Data Report). Total dissolved organic nitrogen in northern North Pacific assessed by a high-temperature combustion method.

Lee, C. and S.M. Henrichs (Background paper). How the nature of dissolved organic matter might affect the analysis of dissolved organic carbon.

Miller, A.E.J., R.F.C. Mantoura and M.R. Preston (Data Report). Shipboard investigation of DOC in the N.E. Atlantic using platinum based catalysts in a Shimadzu TOC-500. HTCO analyzer.

Peltzer, E.T. and P.G. Brewer (Data Report). Some practical aspects of measuring DOC-sampling artifacts and analytical problems with marine samples.

Peyton, G.R. (Background paper). The free-radical chemistry of persulfate-based total organic carbon analyzers.

Wangersky, P.J. (Background paper). Dissolved organic carbon methods: a critical review.

Williams, P.M. J.E. Bauer, K.J. Robertson, D.M. Wolgast and M.L. Occelli (Data Report). Report on DOC and DON measurements made at SIO, 1988-1991.

ment and separate samples from identical locations in the equatorial Pacific. Fitzwater and Martin, using a $1 \% \mathrm{Pt} / \mathrm{Al}_{2} \mathrm{O}_{3}$ catalyst at $680^{\circ} \mathrm{C}$ (Dohrmann Model 190 TC-analyzer) obtained DOC values nearly identical to those measured by $Y$. Suzuki, including surface-water values greater than $200 \mu \mathrm{M}$ in the equatorial Pacific.

The Seattle Workshop was prompted by the impasse in routinely obtaining precise DOC (and DON) values and in order to evaluate the question of whether or not these new, high DOC values are real. Accordingly, N. Andersen, Program Director of the National Science Foundation-Marine Chemistry Division, funded (with assistance from the The National Oceanic \& Atmospheric Administration and the U.S. Department of Energy) a one-year proposal to support the Workshop and the associated intercomparison exercise. It was understood from the outset that results and recommendations from the Workshop would be made available to the oceanographic community in 1992 via a special volume of Marine Chemistry.

\section{Workshop Objectives and Agenda}

The overall intent of the Workshop was to work toward achieving accurate and consistent DOC and DON measurements using standardized methods. It was not meant to be a forum for passing final judgement on the validity of the existing elevated DOC and DON values-although heated discussions on this subject inevitably occurred and some participants took sides.

Five major Workshop objectives were addressed, namely: 1) to define consistent trends among DOC and DON measurements by HTCO and WCO methods, including the intercomparison results; 2) to critically evaluate procedures for collecting, processing and preserving water samples for DOC and DON analysis; 3) to identify, if possible, mechanisms and instrumental operating parameters that bear upon the generation of consistent results from $\mathrm{HTCO}$ and WCO methodologies; 4) to define interim procedures for DOC (and to a lesser extent, DON) measurements in ongoing and imminent field programs such as JGOFS; and 5) to establish guidelines for future research on analytical methodologies.

The Steering Committee invited 40 participants to the Workshop; approximately 50 people attended, including additional scientists and company representatives. Before the meeting each participant was requested to submit a Data Report, if appropriate, detailing relevant, unbiased DOC and/or DON measurements completed in their respective laboratories. In addition, three seawater samples and one river-water sample were collected in Hawaii at the end of March and sent to interested participants for DOC and/or DON analysis before the Workshop. These intercomparison results, plus the results from an on-site comparative DOC analysis of two natural water samples by four commercial manufacturers, were evaluated at the Workshop.

During the workshop, Background Papers (Bauer et al., Lee and Henrichs, Peyton, and Wangersky; see Table 1) and Intercomparison results (J. Hedges) were presented. In addition, four working subgroups met for three days to discuss and prepare written reports on DOC analysis, DON analysis, analyzer mechanisms for both HTCO and WCO methodologies, and sample processing and preparation. These detailed reports, plus the Background Papers, Data Reports, and Intercomparison results, will be published in 
the volume of Marine Chemistry due out in early Fall 1992.

\section{Some Highlights of the Working Subgroup Discussions}

\section{DOC Analysis}

The absolute accuracy of current DOC measurements is unknown. If we are to determine the size of oceanic DOC pools and monitor secular changes and spatial variations within these pools, the analytical accuracy must be $\geq 99 \%$ and the corresponding precision on the order of $1 \%$. For example, if one-half of the yearly $\mathrm{CO}_{2}-\mathrm{C}$ oceanic input of $3 \times 10^{15} \mathrm{~g}$ (50\% of the anthropogenic $\mathrm{CO}_{2}-\mathrm{C}$ flux from fossil-fuel burning and deforestation) were to accumulate in the DOC pool $(\sim 2$ $\times 10^{18} \mathrm{~g}$ ), its annual increase would be $0.075 \%$, equivalent to a decadal DOC increase in all oceans and seas of $\sim 0.5 \mu \mathrm{M}\left(6.25 \times 10^{16}\right.$ moles/1.37 $\times 10^{21}$ liters). Obviously, less precision is required to monitor the short-term biological DOC fluxes ( $\geq 1 \mu \mathrm{M} \mathrm{d}^{-1}$ ) associated with primary production and heterotrophic consumption. Currently, the precision reported for $\mathrm{WCO}$ and $\mathrm{HTCO}$ measurements varies from 1.5 to $5 \mu \mathrm{M} \mathrm{C}$.

Due to the absence of appropriate standards, establishing absolute accuracy from existing HTCO and WCO methodologies does not appear probable at this time; hence, referee methods, such as sealed-tube combustion and CHN (carbon, hydrogen, nitrogen) analysis of dissolved-organicmatter isolates (Alperin and Martens; Fry et al., see Table 1), must be made in conjunction with HTCO measurements. It can be argued that sealed-tube combustions avoid seawater matrix effects, have been shown to quantitatively oxidize such refractory substances as graphite and diamonds, and permit determination of isotopic ratios $\left(\delta^{13} \mathrm{C}, \delta^{15} \mathrm{~N}\right)$ for testing completeness of oxidation.

The appropriate procedures for obtaining reproducible analytical blanks, working standards. and reference samples, including the protocols to be established for quality assurance, are vitally needed for the current DOC (and DON) methodologies and for attempts-probably futile-to relate current results to historical DOC data sets.

System blanks in HTCO analyzers include $\mathrm{DOC}$ in the carrier and purge gases, in the $\mathrm{HCl}$ or $\mathrm{H}_{3} \mathrm{PO}_{4}$ used for acidification and in the distilled water or seawater used for standardization. Perhaps most importantly, system blanks may result from $\mathrm{CO}_{2}$ produced from superheated steam and $\mathrm{O}_{2}$ reacting with organic matter bound to combustion tube substrates. Ideally, reinjection of condensed water exiting the combustion tube should establish the overall system blank assuming negligible salt effects. Using this technique, Suzuki et al. (1992) have measured blanks on the order of $3 \mu \mathrm{M} \mathrm{C}$, while Benner and Strom (see Table 1) report blanks on the order of $30-50 \mu \mathrm{M} \mathrm{C}$. Alternatively, using carbon-free distilled water would avoid contamination problems inherent in collecting water exiting the combustion tube. Another tactic is to reduce the volume of a seawater sample by freeze-drying followed by reinjection, but such evaporative procedures are highly prone to contamination (Fry et al., see Table 1) and also may result in the loss of volatile organic substances.

Working calibration standards (e.g., potassium acid phthalate, glucose and ethylenediamine tetraacetic acid) should be made up in DOC (and DON)-free distilled water and their instrumental detector responses checked concurrently with a calibrated $\mathrm{CO}_{2}-\mathrm{NO}$ standard gas. Most importantly, a "standard," deep-seawater sample, filtered through a $0.2-\mu \mathrm{m}$-pore-size Nuclepore ${ }^{\circledR}$ filter, sealed in 50-100 $\mathrm{ml}$ amber ampules, and stored at $\sim 5^{\circ} \mathrm{C}$ or frozen at $-20^{\circ} \mathrm{C}$, should be made available to monitor long-term (weeks to months) instrumental and blank variability during cruises, etc.-provided there are no significant longterm changes in its DOC content. Conceivably, such a seawater sample could double as an interlaboratory comparison standard. However, an alternate reference material (e.g., $N$-acetyl-glucosamine) may also be necessary. In any event, a rigorously controlled protocol needs to be established for inter-laboratory standardization.

The question of whether there is or is not compelling evidence that HTCO methods are measuring a major DOC component missed by WCO techniques was debated at length at the Workshop, sometimes acrimoniously. The following salient facts emerged from a tabulation of DOC concentrations (taken from published papers, preprints, and the reports in Table 1) in natural waters analyzed by both HTCO and WCO: 1) HTCO methods almost always give higher estimates of DOC than WCO [ultraviolet (UV) or persulfate] methods: 2) HTCO oxidations of seawater samples previously oxidized by UV or persulfate give an additional increment of DOC equal to the difference $( \pm 10 \%)$ between DOC initially measured by both HTCO and WCO; 3 ) in a number of cases, a high HTCO system blank could account for the differences between HTCO and WCO measurements (see Intercomparisons section below), notably in deep water, and especially at the $\mathrm{O}_{2}$ minimum: 4) discrepancies as high as $100-200 \%$ between HTCO and WCO values are most prevalent in open-ocean, as opposed to coastal, surface waters: and 5) significant differences in HTCO and WCO measurements of DOC in fresh $\left(\mathrm{Cl}^{-}\right.$-free) waters generally were not noted. Whether $\mathrm{Cl}^{-}$effects and/or variations in the molecular nature of DOC between open-ocean and fresh or coastal waters cause these converging $\mathrm{HTCO}$ and $\mathrm{WCO}$ values are questions that need to be examined.

\author{
... the analytical \\ accuracy must be \\ $\geqslant 99 \%$ and the \\ corresponding \\ precision on the order \\ of $1 \%$.
}




\section{$H_{\text {igh-temperature }}$}

oxidation kinetics ...

are a "black box" ...

\section{DON Analysis}

Much of the above discussion of accuracy, precision, blanks, standards, and reference samples for DOC also applies to DON. Because DON is generally a small fraction of the total dissolved nitrogen $\left(\mathrm{TDN}=\mathrm{DON}+\mathrm{NO}_{3}^{-}+\mathrm{NO}_{2}^{-}+\mathrm{NH}_{3}\right.$ ), especially in deep water, and is determined by subtracting total dissolved inorganic nitrogen (TDIN $=\mathrm{NO}_{3}^{-}+\mathrm{NO}_{2}^{-}+\mathrm{NH}_{3}$ ) from the measured values of TDN, various suggestions were made to improve accuracy and precision by removing $\mathrm{NO}_{3}^{-}, \mathrm{NO}_{2}^{-}$and $\mathrm{NH}_{3}$ before $\mathrm{HTCO}$ analysis of DON. As with DOC, independent verifications of HTCO measurements using sealed-tube combustions and/or $\mathrm{CHN}$ analyses of isolated dissolved organic matter (DOM) constituents were recommended.

Discussions about the stoichiometry of DOC: DON:DOP (DOP = dissolved organic phosphorus) vis-à-vis the Redfield ratio (106:16:1) pointed out that $\mathrm{C} / \mathrm{N}$ ratios range from $12-30$ in oligotrophic surface waters (I. Koike, D. Karl, and S. Fitzwater, personal communication) to 5-11 in high-nutrient, upwelled coastal and equatorial waters (Y. Suzuki and S. Fitzwater, personal communication) and thus, there is no reason to necessarily expect high DON concentrations to occur where elevated DOC values have been measured by HTCO. The high DON concentrations reported by Suzuki et al. (1985) and Sugimura and Suzuki (1988) predicate elevated DOP concentrations as well (Jackson, 1988), but to date attempts to detect high DOP values have been unsuccessful (Y. Suzuki, personal communication; Karl et al., see Table 1). Clearly, DOC:DON: DOP ratios measured by HTCO or WCO methods will ultimately have to be consistent with the $C$, $\mathrm{N}$ and $\mathrm{P}$ contents of the various constituents of DOM (e.g., carbohydrate and protein-containing compounds, humic substances and as yet unidentified organic matter).

This leads to the thorny question of whether or not HTCO methods give higher DON values than the conventional wet chemical techniques (UV or persulfate). The high DON concentrations (30-40 $\mu \mathrm{M}$ ) reported by Suzuki et al. (1985) and Sugimura and Suzuki (1988) in the surface waters of the Western Pacific were five to ten times higher than one might anticipate: yet these same concentration factors were two to three times lower than those measured for DOC by HTCO versus WCO techniques in the same seawater samples. Some high DON concentrations (up to $20 \mu \mathrm{M}$ ), however, have been measured in surface waters during the 1989 JGOFS North Atlantic Spring Bloom Experiment and in the equatorial Pacific (Fitzwater and Martin. see Table 1; Y. Suzuki and S. Fitzwater, personal communication) using HTCO coupled with spectrophotometric detection of $\mathrm{NO}_{3}^{-}$. In contrast to the above elevated
DON concentrations, Walsh (1989) found no significant differences in DON concentrations in Hawaiian surface waters measured by HTCO (Antek model 771 TDN-analyzer, $1,100^{\circ} \mathrm{C}$, chemiluminescent detection) and by WCO (UV or persulfate). In fact, other HTCO measurements of DON in surface and deep waters of the Atlantic and Pacific using Suzuki-clones at $680^{\circ} \mathrm{C}$ (Williams et al.; Hansell, see Table 1), a Sumigraph model N-200 TDN analyzer at $800^{\circ} \mathrm{C}$ (Maita and Yanada, 1990), or a Yanatec TN-7 TDN analyzer at $800^{\circ} \mathrm{C}$ (Koike and Tupas, see Table 1 ) have all given DON concentrations of the same order as measured by WCO methodologies. These latter results led the DON Working Subgroup to state that there is little compelling evidence in support of high $(>30 \mu \mathrm{M})$ DON values.

\section{Analyzer Mechanisms}

High-temperature oxidation kinetics for converting DOM to analytically measurable gases $\left(\mathrm{CO}_{2}, \mathrm{NO}\right.$, and $\left.\mathrm{NO}_{2}\right)$ are a "black box" in terms of delineating the reactions occurring within combustion tubes. Are Pt or other heavy metal catalysts necessary? What are the sources of oxygen for combustion? What is the molecular composition of the gases exiting the combustion tube? How are the oxidation kinetics affected by the flash evaporation of injected water?

Enhanced oxidation of DOC (and DON) using a variety of combustion tube packings (e.g., Pt gauze, $\mathrm{Co} / \mathrm{CoO}, 0-3 \%$ Pt on alumina or aluminosilicates, silica chips) has been reported (Williams et al.; Miller et al.; Peltzer and Brewer; see Table 1). These results were generally $10-30 \mu \mathrm{MC}$ lower than Y. Suzuki's measurements, but of the same magnitude as values determined by sealedtube combustion (M. Alperin, personal communication). It was evident that mass spectrometric identification of the exit gases generated by different combustion-tube packings at various temperatures $\left(680-1,100^{\circ} \mathrm{C}\right)$ is of high priority. Conceivably, oxidation at $1,100^{\circ} \mathrm{C}$ in a ceramic tube charged with high-surface-area, inert packings could eliminate the need for expensive Pt catalysts, whose primary function in high-temperature oxidations is purported to be the conversion of $\mathrm{CO}$ and graphitic carbon to $\mathrm{CO}_{2}$ (M. Occelli, personal communication; see also Bauer et al., Table 1).

The role of $\mathrm{O}_{2}$ or air as the carrier gas in HTCO was also questioned. F. Hoek (personal communication) noted that the Ionics TC-analyzers have given the same DOC results whether $\mathrm{N}_{2}$ or $\mathrm{O}_{2}$ was used as the carrier gas. This rather surprising fact is easily checked and if confirmed with other HTCO analyzers, says that the injected water provides oxygen for combustion. Isotopic tracking of ${ }^{18} \mathrm{O}$-labeled oxidants $\left(\mathrm{O}_{2}\right.$ carrier gas, $\left.\mathrm{H}_{2} \mathrm{O}, \mathrm{CuO}\right)$ should unequivocally resolve this question. $\mathrm{Di}$ rectly related to this is the effect that flash evap- 
oration of $100 \mu \mathrm{l}$ of water at injection has upon the instantaneous partial pressure of $\mathrm{O}_{2}$ in the combustion tube $\left(\mathrm{O}_{2}\right.$ partial pressure will drop by a factor of $10^{4}$ to $10^{5}$ for $100 \mu \mathrm{l}$ of $\mathrm{H}_{2} \mathrm{O}$ vaporizing to $\sim 400 \mathrm{~cm}^{3}$ at $1,000^{\circ} \mathrm{C}$ in a 50 -ml-void-volume combustion tube). This effect could result in unoxidized DOM being initially deposited within the combustion tube and/or being swept through the tube as intact thermally cracked fragments before re-establishment of normal $\mathrm{O}_{2}$ partial pressures.

A discussion of WCO reactions (UV and persulfate) emphasized the fact that these are primarily free radical systems (sulfate and hydroxyl radicals, $\mathrm{SO}_{4}^{*}$ and $\mathrm{OH}^{*}$ ) which, in theory, are dominated in seawater by reactions of $\mathrm{OH}^{*}$ and $\mathrm{SO}_{4}^{*}$ with $\mathrm{Cl}^{-}$and dissolved organic matter. On the basis of thermodynamic arguments. Peyton (see Table 1) states that $\mathrm{Cl}^{-}$should scavenge $>99 \%$ of the $\mathrm{SO}_{4}^{*}$, leaving only traces to attack DOM. However, the fact remains that a wide variety of organic compounds are efficiently oxidized by persulfate when "spiked" in seawater systems. Peyton (see Table 1) also pointed out that selective oxidation of seawater DOM by $\mathrm{SO}_{4}^{*}$ and/or $\mathrm{OH}^{*}$ may result, via sequential electrophilic reactivity. in DOM residues rich in carboxyl groups. These residues would be resistant to further radical attack and hence would be incompletely oxidized. Complexation of $\mathrm{Cl}^{-}$with $\mathrm{Hg}^{2+}$ enhances the rate of wet oxidation of acetic acid and natural DOM in seawater with UV and persulfate (Bauer et al., 1991, and personal communication) supporting the concept of $\mathrm{Cl}^{-}$interference with free radical oxidation. Thus it appears that both UV and persulfate oxidations are $\mathrm{O}_{2}$ limited-yet relatively complete UV oxidation of DOC was reported ( $P$. Williams, personal communication) to occur in $\mathrm{N}_{2}$-saturated seawater, giving results comparable to those measured in identical $\mathrm{O}_{2}$-saturated samples. Clearly, our knowledge of WCO mechanisms are fragmentary and even inaccurate. Optimization of free radical oxidants could well result in WCO oxidations with efficiencies equivalent to HTCO methods,

Additional discussions on how the physical and chemical characteristics of DOM (e.g., molecular weight and size, polymeric structure, halogenation of DOM, etc.) could affect yields of measurable oxidation products from HTCO and WCO combustions of DOM are included in the working Subgroup report on Analyzer Mechanisms (see the special volume of Marine Chemistry).

\section{Sample Processing and Preservation}

A number of detailed recommendations were made by this subgroup concerning sample collection, filtration, preservation, storage and contamination problems. Common sense dictates a number of these procedures. most of which are currently observed-or should be-and are itemized in the Workshop Report.

It is especially important to minimize DOC and DON losses due to adsorption on vessel walls, flocculation and precipitation and biological processes. Losses of DOC, by whatever process, from filtered, acidified and refrigerated seawater samples sealed in precombusted glass ampules averaged $\sim 5 \mu \mathrm{M}$ for the intercomparison samples, as analyzed by HTCO (Shimadzu model 5000 TCanalyzer, R. Benner, personal communication) over a 10-week period, and $7 \pm 2 \mu \mathrm{M}$ for surface seawater (Scripps Institution of Oceanography Pier, original DOC $=100 \mu \mathrm{M})$ stored at $4^{\circ} \mathrm{C}$ for 4 months (Suzuki-clone analyzer, Williams et al., see Table 1). This latter time series included acidified samples stored at $-20^{\circ} \mathrm{C}$ and non-acidified aliquots stored at $4^{\circ} \mathrm{C}$ and $-20^{\circ} \mathrm{C}$, in which DOC losses were $7 \pm 2,2 \pm 0$ and $0 \pm 2 \mu \mathrm{M}$, respectively. Shipboard HTCO (Suzuki-clone) analysis of filtered, non-acidified samples from 50 and 3,200 $\mathrm{m}$ in the Sargasso Sea showed DOC losses of 3 $\pm 2 \mu \mathrm{M}(50 \mathrm{~m})$ and $7 \pm 2 \mu \mathrm{M}(3,200 \mathrm{~m})$ when stored for $24 \mathrm{hrs}$ in the dark at $25^{\circ} \mathrm{C}$ (Williams et al., see Table 1). These above DOC losses are similar to those reported by Sugimura and Suzuki (1988) for a filtered and acidified seawater sample (original DOC $=100 \mu \mathrm{M}$ ) stored for 6 days at $4^{\circ} \mathrm{C}$ or $25^{\circ} \mathrm{C}$, whereas in a frozen aliquot they found a $15 \mu \mathrm{M}$ reduction in DOC. In summary, there are no consistent trends in DOC losses using different storage techniques.

Adsorption and/or flocculation losses are difficult to catagorize in filtered seawater samples, but they are undoubtedly more prevalent in highproductivity surface waters containing relatively high concentrations of surface-active organics. Acidification itself can cause precipitation of humic acids and induce flocculation of DOM. High-temperature oxidation by both injection and sealed-tube combustion techniques could, potentially, reveal the magnitude of adsorption and flocculation losses.

Biological losses of DOC and DON through heterotrophic oxidation by micro-organisms to $\mathrm{CO}_{2}$ and inorganic $\mathrm{N}$-compounds is axiomatic (e.g., Sugimura and Suzuki, 1988, reported DOC losses of up to $30 \%$ in 6 days for unfiltered aliquots of their seawater samples). Removal of all or a significant fraction of the micro-organisms by filtration thru $0.2-1 \mu \mathrm{M}$ pore diameter polycarbonate (Nuclepore) or glass fiber (Whatman) filters, coupled with poisoning by $\mathrm{HgCl}_{2}$ (when it is appropriate and does not harm the catalysis) is mandatory, especially in surface seawaters and sedimentary pore waters.

In any event. immediate filtration and shipboard analysis (within the hour) for both DOC and DON is preferable to sample preservation, primarily to avoid adsorption and flocculation
Clearly, our

knowledge of WCO

[wet combustion]

mechanisms are

fragmentary and even

inaccurate. 
Table 2

Specifications for DOC analyses of the Hawaii reference samples.

\begin{tabular}{|c|c|c|c|c|c|c|c|c|}
\hline $\begin{array}{l}\text { Workshop } \\
\text { Participant }\end{array}$ & $\begin{array}{c}\text { Analyst } \\
\text { Name }\end{array}$ & $\begin{array}{c}\text { Analyzer } \\
\text { Type }\end{array}$ & Analyzer Model & $\begin{array}{c}\text { Reaction } \\
\text { Temperature, } \\
{ }^{\circ} \mathrm{C}\end{array}$ & $\begin{array}{c}\text { Catalyst } \\
\text { Type }\end{array}$ & $\begin{array}{c}\mathrm{Wt} \% \\
\mathrm{Pt}\end{array}$ & $\begin{array}{l}\text { Oxidant } \\
\text { Species }\end{array}$ & $\begin{array}{c}\text { Reacted } \\
\text { Volume, } \mu \mathrm{L}\end{array}$ \\
\hline Alperin & Alperin & HTCO & Shimadzu TOC-5000 & 680 & Normal Pt & 0.5 & $\mathrm{O}_{2}$ & 100 \\
\hline Alperin & Alperin & HTCO & Sealed tube & 850 & $\mathrm{CuO} / \mathrm{Ag}$ & 0 & $\mathrm{O}_{2}$ & 3,000 \\
\hline Benner & Strom & HTCO & Shimadzu TOC-5000 & 680 & Normal Pt & 0.5 & $\mathrm{O}_{2}$ & 200 \\
\hline Burdige & Homstead & HTCO & Shimadzu TOC-5000 & 680 & Normal Pt & 0.5 & $\mathrm{O}_{2}$ & 100 \\
\hline Cauwet & Cauwet & HTCO & Shimadzu TOC-5000 & 680 & $\mathrm{Pt} / \mathrm{Al}_{2} \mathrm{O}_{3}$ & 3 & $\mathrm{O}_{2}$ & 100 \\
\hline Doering & McKenna & WCO & OI 700-TOC & 100 & None & 0 & $\mathrm{~K}_{2} \mathrm{~S}_{2} \mathrm{O}_{8}$ & 343 \\
\hline Ertel & Ertel & HTCO & Ionics 555 & 680 & $\mathrm{Pt}$ & 100 & $\mathrm{O}_{2}$ & 100 \\
\hline Fry & Fry & HTCO & Sealed tube & 590 & $\mathrm{PtCl}_{6}$ & $?$ & $\mathrm{CuO}$ & $2,000-18.000$ \\
\hline Hansell & Hansell & HTCO & HM Suzuki Clone & 710 & $\mathrm{Pt} / \mathrm{Al}_{2} \mathrm{O}_{3}$ & 3 & $\mathrm{O}_{2}$ & 100 \\
\hline Hegeman & Hegeman & WCO & OI 700-TOC & 100 & None & 0 & $\mathrm{~K}_{2} \mathrm{~S}_{2} \mathrm{O}_{8}$ & 1,000 \\
\hline Hopkinson & Padien & HTCO & Ionics 1500 & 770 & $\mathrm{Pt}$ & 100 & $\mathrm{O}_{2}$ & 161 \\
\hline Ionics & Ghotbi & HTCO & Ionics 555 & 795 & $\mathrm{Pt}$ & 100 & $\mathrm{O}_{2}$ & 100 \\
\hline Ittekkot & Raabe & HTCO & Carlo Erba TOM-480 & 1,020 & $\mathrm{NiO}$ & 0 & $?$ & $9,000 /$ cycle \\
\hline Kahler & Kahler & HTCO & Dimatek TOC-100 & 900 & Pt wool & 100 & $\mathrm{O}_{2}$ & 100 \\
\hline Karl & Tien & HTCO & Ionics 555 & 780 & $\mathrm{Pt}$ & 100 & $\mathrm{O}_{2}$ & 100 \\
\hline Mantoura & S. Jones & wCO & HM Automatic UV/P & 100 & None & 0 & $\mathrm{UV} / \mathrm{K}_{2} \mathrm{~S}_{2} \mathrm{O}_{8}$ & 10,000 \\
\hline Martin & Fitzwater & HTCO & Dohrmann DC-190 & 680 & $\mathrm{Pt}$ & ? & $\mathrm{O}_{2}$ & 50 \\
\hline McCorkle & Martin & HTCO & HM Suzuki Clone & 800 & Pt-gauze & 100 & $\mathrm{O}_{2}$ & 300 \\
\hline Miller & Mantoura & wCO & HM Automatic UV-P & 100 & None & 0 & $\mathrm{UV} / \mathrm{K}_{2} \mathrm{~S}_{2} \mathrm{O}_{8}$ & 4,000 \\
\hline Miller & Mantoura & HTCO & Shimadzu TOC-500 & 680 & Normal Pt & 0.5 & $\mathrm{O}_{2}$ & 80 \\
\hline Norrman & Norrman & HTCO & Shimadzu TOC-5000 & 680 & Normal Pt & 0.5 & $\mathrm{O}_{2}$ & 100 \\
\hline Peltzer & Peltzer & HTCO & HM Suzuki Clone & 800 & $\mathrm{Pt} / \mathrm{Al}_{2} \mathrm{O}_{3}$ & 5 & $\mathrm{O}_{2}$ & 100 \\
\hline Perdue & Lu Sun & HTCO & Coulometrics $5020-\mathrm{TC}$ & 900 & $\mathrm{BaCrO}_{3}$ & 0 & $\mathrm{O}_{2}$ & 200 \\
\hline Rosemont & Ton & HTCO & Dohrmann DC-190 & 680 & $\mathrm{Pt} / \mathrm{Al}_{2} \mathrm{O}_{3}$ & 1 & $\mathrm{O}_{2}$ & 100 \\
\hline Spitzy & Fengler & HTCO & Ionics 555 & 800 & $\mathrm{Pt}$ & 100 & $\mathrm{O}_{2}$ & 100 \\
\hline Suzuki & Suzuki & HTCO & Sumigraph TOC -90 & 680 & $\mathrm{Pt} / \mathrm{Al}_{2} \mathrm{O}_{3}$ & 3 & $\mathrm{O}_{2}$ & 50 \\
\hline Tanouc & Tanoue & HTCO & Sumigraph TOC-90 & 680 & $\mathrm{Pt} / \mathrm{Al}_{2} \mathrm{O}_{3}$ & 3 & $\mathrm{O}_{2}$ & 100 \\
\hline Tugrul & Morkoc & HTCO & Shimadzu TOC-500 & 680 & HiSens Pt & $?$ & $\mathrm{O}_{2}$ & 200 \\
\hline Tugrul & Hatipoglu & wCO & Technicon AII & 100 & None & 0 & $\mathrm{UV} / \mathrm{K}_{2} \mathrm{~S}_{2} \mathrm{O}_{8}$ & 1,500 \\
\hline Walsh & Walsh & wCO & OI $700-\mathrm{TOC}$ & 100 & None & 0 & $\mathrm{~K}_{2} \mathrm{~S}_{2} \mathrm{O}_{8}$ & 2.600 \\
\hline Wangersky & Chen & HTCO & HM Suzuki Clone & 710 & $\mathrm{Pt} /$ Kaowool & 5 & $\mathrm{O}_{2}$ & 100 \\
\hline Wangersky & Chen & WCO & HM Automatic UV/P & 100 & None & 0 & UV & 4,000 \\
\hline PM Williams & Wolgast & HTCO & HM Suzuki Clone & 680 & $\mathrm{Pt} / \mathrm{Al}_{2} \mathrm{O}_{3}$ & 3 & $\mathrm{O}_{2}$ & 100 \\
\hline PM Williams & Wolgast & HТCO & HM Suzuki Clone & 680 & $\mathrm{~A}_{1 S \mathrm{SIO}_{4}}$ & 0 & $\mathrm{O}_{2}$ & 100 \\
\hline
\end{tabular}

$\mathrm{HTCO}=$ high temperature catalytic oxidation, $\mathrm{WCO}=$ wet chemical oxidation, $\mathrm{HM}=$ home made, $\mathrm{UV} / \mathrm{P}=\mathrm{UV} /$ persulfate.

Table 3

Specifications for DON analyses of the Hawaii reference samples.

\begin{tabular}{|c|c|c|c|c|c|c|c|c|c|c|}
\hline $\begin{array}{l}\text { Workshop } \\
\text { Participant }\end{array}$ & $\begin{array}{l}\text { Analyst } \\
\text { Name }\end{array}$ & $\begin{array}{l}\text { Date of } \\
\text { Analysis }\end{array}$ & $\begin{array}{c}\text { Analyzer } \\
\text { Type }\end{array}$ & Analyzer Model & Detector Model & $\begin{array}{c}\text { Reaction } \\
\text { Temperature, } \\
{ }^{\circ} \mathrm{C}\end{array}$ & $\begin{array}{c}\text { Catalyst } \\
\text { Type }\end{array}$ & $\begin{array}{c}\mathrm{Wt} \% \\
\mathrm{Pt}\end{array}$ & $\begin{array}{l}\text { Oxidant } \\
\text { Species }\end{array}$ & $\begin{array}{c}\text { Reacted } \\
\text { Volume, } \mu \mathrm{L}\end{array}$ \\
\hline Antek & R. Jones & $7 / 4$ & HTCO & Antek $7000 \mathrm{~N}$ & Antek $7000 \mathrm{~N}$ & 1,050 & None & 0 & $\mathrm{O}_{2}$ & 5 \\
\hline Cifuentes & Veneroni & $6 / 11$ & $\mathrm{HTCO}$ & Shimadzu TOC-500 & Antek $720 \mathrm{~N}$ & 680 & Normal Pt & 0.5 & $\mathrm{O}_{2}$ & 50 \\
\hline Fry & Fry & $5 / 25$ & HTCO & Sealed Tube & Manometric & 590 & $\mathrm{PtCl}_{6}$ & $?$ & $\mathrm{CuO}$ & $2,000-18,000$ \\
\hline Hansell & Hansell & $4 / 29$ & $\mathrm{HTCO}$ & HM Suzuki Clone & Antek 720 & 710 & $\mathrm{Pt} / \mathrm{Al}_{2} \mathrm{O}_{3}$ & 3 & $\mathrm{O}_{2}$ & 100 \\
\hline Kahler & Koeve & $7 / 9$ & $\mathrm{HTCO}$ & Dimatek TOC-100 & Antek 720 & 900 & $\mathrm{Pt}$ & 100 & $\mathrm{O}_{2}$ & 100 \\
\hline Karl & Dore/Karl & $7 / 7$ & $\mathrm{HTCO}$ & Antek 771 & Antek 720 & 1,100 & None & 0 & $\mathrm{O}_{2}$ & 10 \\
\hline Koike & Tupus/Koike & $7 / 1$ & HTCO & Yanatec TN-7 & Chemiluminescent & 800 & $\mathrm{MnO}_{2}$ & 0 & $\mathrm{O}_{2}$ & 40 \\
\hline Martin & Fitzwater & $4 / 23-30$ & $\mathrm{HTCO}$ & Dohrmann DC-190 & Spectrophotometric & 683 & $\mathrm{Pt}$ & $?$ & $\mathrm{O}_{2}$ & 200 \\
\hline Suzuki & Suzuki & $7 / 27-28$ & $\mathrm{HTCO}$ & Sumigraph TOC-90 & Spectrophotometric & 680 & $\mathrm{Pt} / \mathrm{Al}_{2} \mathrm{O}_{3}$ & 3 & $\mathrm{O}_{2}$ & 400 \\
\hline Walsh & Walsh & $?$ & WCO & UV & Autoanalyzer & 84 & None & 0 & $\mathrm{UV} / \mathrm{H}_{2} \mathrm{O}_{2}$ & 20,000 \\
\hline Walsh & Walsh & ? & WCO & $\mathrm{K}_{2} \mathrm{~S}_{2} \mathrm{O}_{8} /$ autoclave & Autoanalyzer & 100 & None & 0 & $\mathrm{~K}_{2} \mathrm{~S}_{2} \mathrm{O}_{8}$ & 5.000 \\
\hline Williams & Wolgast & $4 / 10$ & HTCO & HM Suzuki Clone & Antek 720 & 680 & $\mathrm{Pt} / \mathrm{Al}_{2} \mathrm{O}_{3}$ & 3 & $\mathrm{O}_{2}$ & 100 \\
\hline Williams & Wolgast & $4 / 12$ & $\mathrm{HTCO}$ & HM Suzuki Clone & Antek 720 & 680 & $\mathrm{AlSiO}_{4}$ & 0 & $\mathrm{O}_{2}$ & 100 \\
\hline
\end{tabular}

Abbreviations are same as in Table 2 . 
losses, and the possible salting-out of DOM in frozen samples.

\section{Intercomparisons: Pre-Workshop and On-Site}

The Pre-Workshop, single-blind intercomparison exercise was conducted using $10.5-\mathrm{m}, 766$ $\mathrm{m}$ (approximately at the $\mathrm{O}_{2}$ minimum), and 4,001-m seawater samples collected in late March at the Hawaiian Ocean Time-Series (HOTS) station north of Oahu and a single freshwater sample collected from the Waimea River (Oahu). The seawater was collected with 10-1 Niskin bottles fitted with Teflon-coated closure springs (or a polyethylene carboy for the river sample), gravity-filtered through precombusted $0.70-\mu \mathrm{M}$-nominalpore-size Whatman GF/F (glass fiber) filters into a clean 10-1 carboy and acidified to $\mathrm{pH} 2.5$ with $85 \%$ phosphoric acid. A total of $30015-\mathrm{ml}$ aliquots of each sample were sealed in $20-\mathrm{ml}$ precombusted glass ampules and refrigerated at $5^{\circ} \mathrm{C}$ before mailing to participants. Five ampoules of all four water types were sent on "blue ice" by express mail to interested participants for analysis prior to the Workshop. DOC losses during storage were $<5$ $\mu \mathrm{M}$ (see above) suggesting minimal remineralization and/or precipitation and sorption losses, even through some of the sample sets had warmed to room temperature by the time of receipt.

There were 34 DOC analyses involving over 20 different instrument types (including both HTCO and WCO analyzers) operated in 28 participating laboratories (Table 2). An additional thirteen DON analyses of the same samples were made using nine different instruments (Table 3) in eleven laboratories. The raw data for DOC and DON in the seawater and river samples are depicted in Figs. 1 and 2.

The manufacturer's single-blind, on-site DOC intercomparison used a freshwater sample from Portage Bay, Lake Washington, and a 2-monthold unpreserved, unacidified, refrigerated surfaceseawater sample from the Sargasso Sea. These two samples were analyzed before and after spiking with $400 \mu \mathrm{M} \mathrm{C}$ (as glucose) using three HTCO analyzers and one WCO analyzer (Table 4). These raw data are plotted in Fig. 3.

The Workshop intercomparison of the Hawaii samples was not intended as a rigorous intercalibration or as a definitive test for UV/persulfateresistant, "new" or "extra" DOC or DON. The exercise was designed to establish the range of variability in the measurement of DOC and DON across the scientific community and to determine patterns in the data that might be related to specific instrument characteristics or laboratory procedures. Measurements were made by both experienced and beginning DOC analysts. All reported data were unidentified as to source.

The precision of the DOC analyses was calculated from percent sample mean deviations

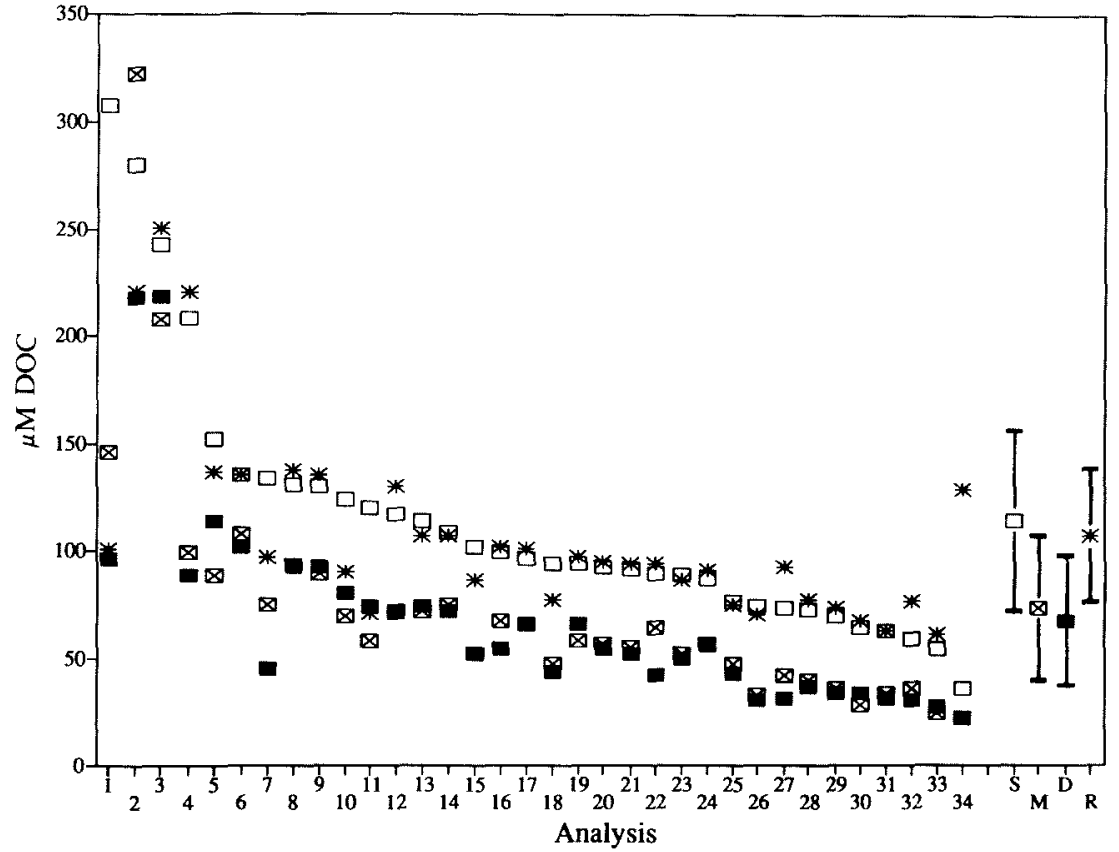

Fig. 1. Trends in measured DOC among 34 analyses of four reference natural water samples. Analyses are listed in order of decreasing concentration for the surface seawater sample. The symbols to the right represent the $( \pm 1$ mean deviation interval) for all analyses of each sample. The sample mean deviation is defined as $(\Sigma|X i-X m|) / n$, where $X m=$ the mean and $n=$ the number of samples analyzed. Symbol codes: open boxes = surface $(10.5 \mathrm{~m})$ seawater, crossed boxes $=$ mid-depth $(766 \mathrm{~m})$ seawater, filled boxes $=$ deep $(4,001 \mathrm{~m})$ seawater, asterisks $=$ river water.

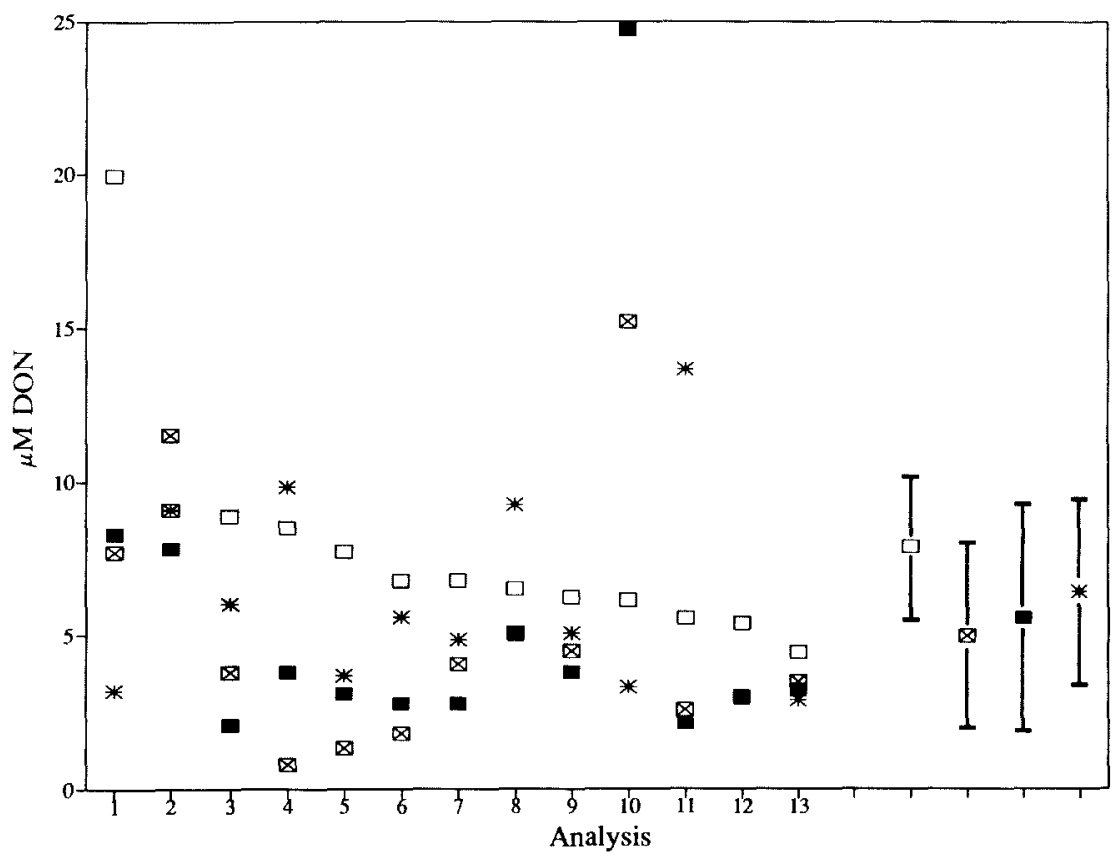

Fig. 2. Trends in measured DON among 13 analyses of the reference natural water samples. Analyses are listed in order of decreasing concentration for the surface seawater sample. Symbols to the right represent the average $( \pm 1$ mean deviation interval) for all analyses of each sample and are designated as in Fig. 1 . 
Table 4

Specifications for DOC analyzers invovled in the manufacturers' comparison.

\begin{tabular}{|c|c|c|c|c|c|c|c|}
\hline $\begin{array}{l}\text { Workshop } \\
\text { Participant }\end{array}$ & $\begin{array}{l}\text { Manufacturing } \\
\text { Company }\end{array}$ & $\begin{array}{l}\text { Analyzer } \\
\text { Model }\end{array}$ & $\begin{array}{c}\text { Reaction } \\
\text { Temperature, } \\
{ }^{\circ} \mathrm{C}\end{array}$ & $\begin{array}{l}\text { Catalyst } \\
\text { Type }\end{array}$ & $\begin{array}{l}\mathrm{Wt} \% \\
\mathrm{Pt}\end{array}$ & $\begin{array}{l}\text { Oxidant } \\
\text { Species }\end{array}$ & $\begin{array}{c}\text { Reacted } \\
\text { Volume } \\
\quad \mu \mathrm{L}\end{array}$ \\
\hline Takahashi & Dohrmann & DC-190 & 680 & $\mathrm{Pt} / \mathrm{Al}_{2} \mathrm{O}_{3}$ & 1 & $\mathrm{O}_{2}$ & 100 \\
\hline Delaney & Shimadzu & TOC -5000 & 680 & Normal Pt & 0.5 & $\mathrm{O}_{2}$ & 150 \\
\hline Hoek & Ionics & 555 & 795 & $\mathrm{Pt}$ & 100 & $\mathrm{O}_{2}$ & 100 \\
\hline Bernard & Ol Analytical & OI $700-\mathrm{TOC}$ & 100 & None & 0 & $\mathrm{Na}_{2} \mathrm{~S}_{2} \mathrm{O}_{8}$ & 1.000 \\
\hline
\end{tabular}

$\left[\% \mathrm{SMD}=\left(\Sigma\left|\mathrm{X}_{1}-\mathrm{M}\right| / \mathrm{nM}\right) 100, \mathrm{M}=\right.$ mean, $\mathrm{n}=$ number of samples] of the five-ampule subsets for each of the four different water types and is presented as \%SMD in Fig. 1. In spite of the relatively high precision, there were disturbingly large ranges and approximately $50 \%$ average variations in the mean DOC concentrations (Fig. 1). The data show that the ranges in variation in the mean DOC concentrations of the same water samples measured in different laboratories by the various HTCO and WCO DOC analyzers were nearly as great as the ranges in variation for the entire data set. Thus, a large component of the overall variability appeared to be operator-related, rather than analyzer-related. The average DOC concentration of the 10-m surface water sample was higher than that measured for the 750- and 4,001-m samples, but did not approach the $220 \mu \mathrm{M}$ DOC value measured by Y. Suzuki (Druffel et al., 1989) for

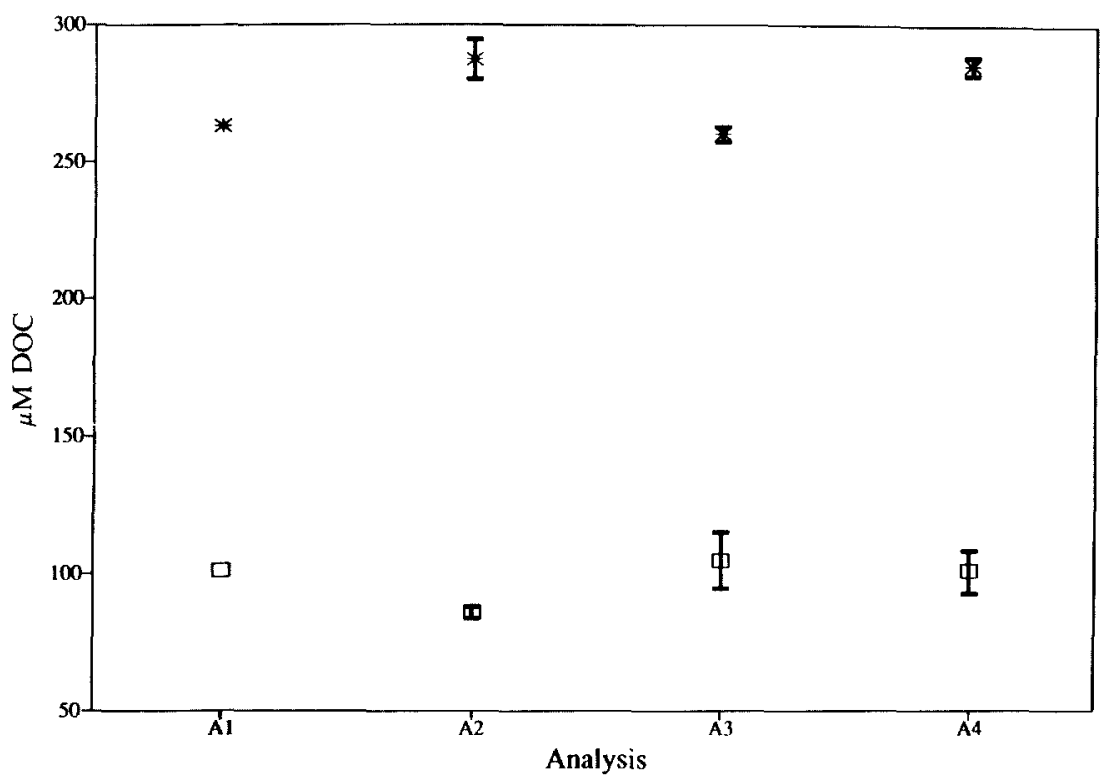

Fig. 3. DOC concentrations measured by four different unidentified commercial instruments (Dohrmann DC-190, Ionics 555, OI 700-TOC and Shimadzu TOC-5000) on freshwater (asterisk) and seawater (open box) samples different from those used for the pre-Workshop comparison. The specifications of these four instruments (purposefully unidentified in this figure) are listed in Table 4. a 20-m frozen sample collected $800 \mathrm{~km}$ north of Hawaii (October 1985) or the $\sim 200-300 \mu \mathrm{M}$ DOC values reported by Sugimura and Suzuki (1988) in the surface waters of the western tropical Pacific. A comparison of DOC concentrations in the Workshop surface $(10-\mathrm{m})$ seawater sample measured by HTCO versus WCO methodologies is depicted in Fig. 4. It is apparent that the 10 highest values are from HTCO, the 3 lowest from WCO, with the remainder falling within a $\sim 50$ $\mu \mathrm{M}$ envelope. The average Waimea River DOC value (Fig. 1) is relatively low versus most rivers, but is not unreasonable considering the volcanic source for this river.

Precision of the DON analyses (\%SMD) were lower than for the DOC measurements (Fig. 2). This may be partially due to the fact that DON is determined by subtracting TDIN from TDN, an important factor in subsurface waters. The DON concentrations for the $10-\mathrm{m}$ surface seawater sample were $\sim 5-20 \mu \mathrm{M}$ (Fig. 2) and did not approach the values of $30-40 \mu \mathrm{M}$ reported by Suzuki et al. (1985) or Sugimura and Suzuki (1988) for surface waters in the western Pacific. In general, the DON Intercomparison data was less precise and ordered than was true for the corresponding DOC measurements.

Several statistical procedures were used to test for patterns within the DOC (Fig. 1) and DON (Fig. 2) data sets. One procedure was the meansubtraction method which is used to test for constant offsets among data from different analyses. In this method, the average of the three seawater concentrations measured in each analysis was determined and subtracted from each of the individual measurements. This treatment cancels out any signal (which could include a blank) common to the three measurements, but preserves the magnitude and direction of the initial concentration differences. After mean subtraction, all but four of the highest data triplets exhibited similar absolute offsets and were well aligned (Fig. 5). One possible explanation for this relationship is that most of the instruments were responding proportionately to the DOC in the four water samples, but that the measured concentrations varied among analyses as a result of instrument blanks of differing magnitudes. The fact that mean sub- 
traction did not align all the DOC data indicates that other variables also existed (e.g., oxidation method, catalyst, and oven temperature) and that blank corrections were not a complete "fix."

A second, more complex procedure, involved offset adjustments of the data followed by rescaling. This treatment of the seawater measurements also indicated the possible presence of blanks whose magnitudes were on the order of 25-50 $\mu \mathrm{M} \mathrm{C}$ (Hedges et al., see Table 1). These blanks are five to ten times higher than those reported by Suzuki et al. (1992) using $3 \% \mathrm{Pt} / \mathrm{Al}_{2} \mathrm{O}_{3}$ catalysis, and J. Bauer (personal communication) using $\mathrm{Co} / \mathrm{CoO}$ catalysis.

Both the mean-subtraction and offset/rescaling treatments did not substantially align the DON data, indicating that variability among different DON analyses did not result primarily from variable blanks.

The manufacturer's on-site DOC intercomparison was set up to determine whether instruments of different design (Table 4) could give similar DOC results for different natural waters when calibrated with the same standards and operated with well-defined blank corrections. The four instrument representatives measured the mean DOC content of the Lake Washington and Sargasso Sea samples with average precisions (SMD) of $5 \%$ and $1 \%$, respectively (Fig. 3). The corresponding average precisions (SMD) for the spiked samples containing $400 \mu \mathrm{M}$ of glucose- $\mathrm{C}$ were better than $2 \%$. Thus, all the commercial instruments gave good to excellent precision and measured similar concentrations of DOC in both samples. The fact that there were no significant differences in DOC concentrations ("extra" DOC) as measured by three HTCO analyzers and one WCO analyzer is equivocal in the case of the Sargasso Sea sample, which had been refrigerated for 2 months. Part or all of the "extra" UV/persulfateresistant DOC, if present, could have been lost from this sample thru remineralization and/or sorption losses during the storage period.

\section{What Was Learned and What Is Next?}

Several salient facts emerged from this workshop. The good news was that seawater samples can be collected, processed, and preserved so that meaningful intercomparisons and/or intercalibrations between laboratories can be undertaken with reasonable confidence in obtaining reproducible results. This is gratifying with respect to comparing current DOC (and, hopefully, DON) measurements from ongoing cruises and laboratory experiments with future measurements. The bad news was the lack of agreement whether any of the standard, "off-the-shelf" DOC (or DON) analyzers could give the accuracy or precision needed to obtain meaningful DOC/DON measurements.

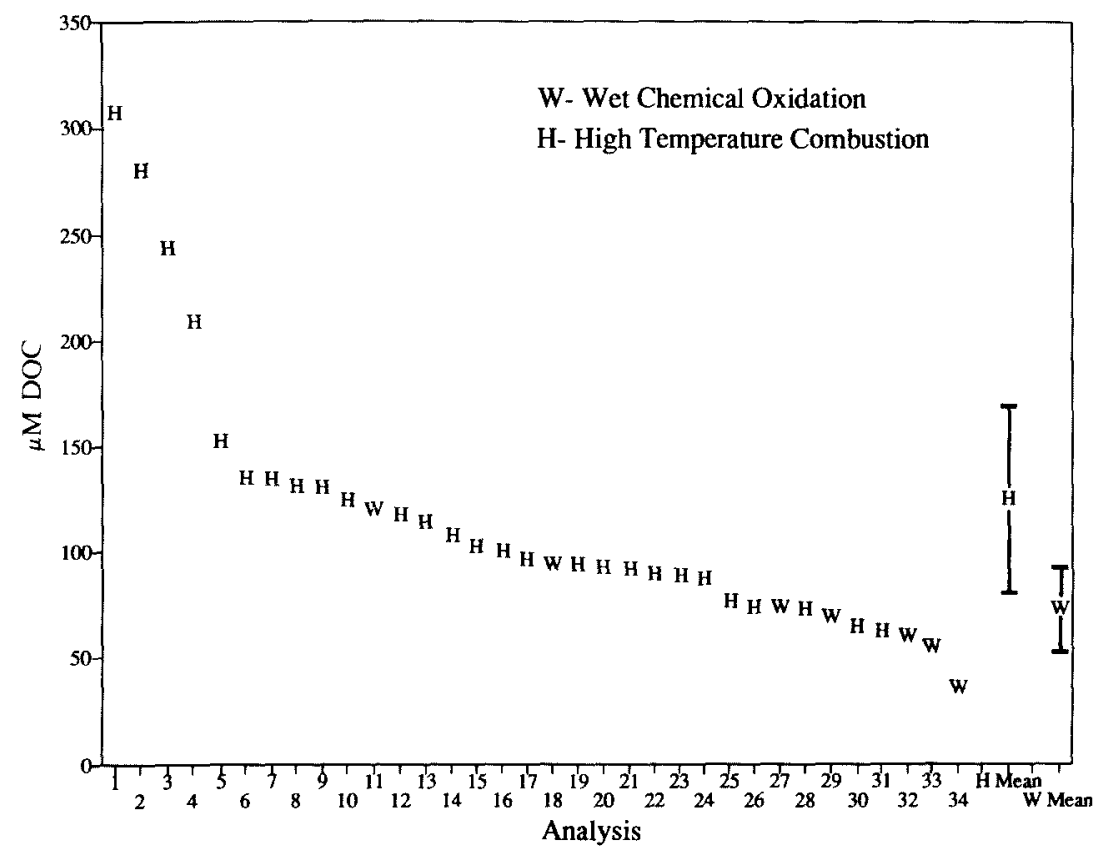

Fig. 4. A comparison of DOC concentrations measured for the surface seawater sample by HTCO $(H)$ versus WCO $(W)$ methods. Symbols to the right represent the average ( \pm 1 mean deviation interval) for the two instrument types.

Of immediate concern is the necessity for additional intercomparison exercises, especially where all analysts and analyzers are identified. These comparison exercises are mandatory for achieving rational protocols in DOC/DON analysis and should be part of projects currently

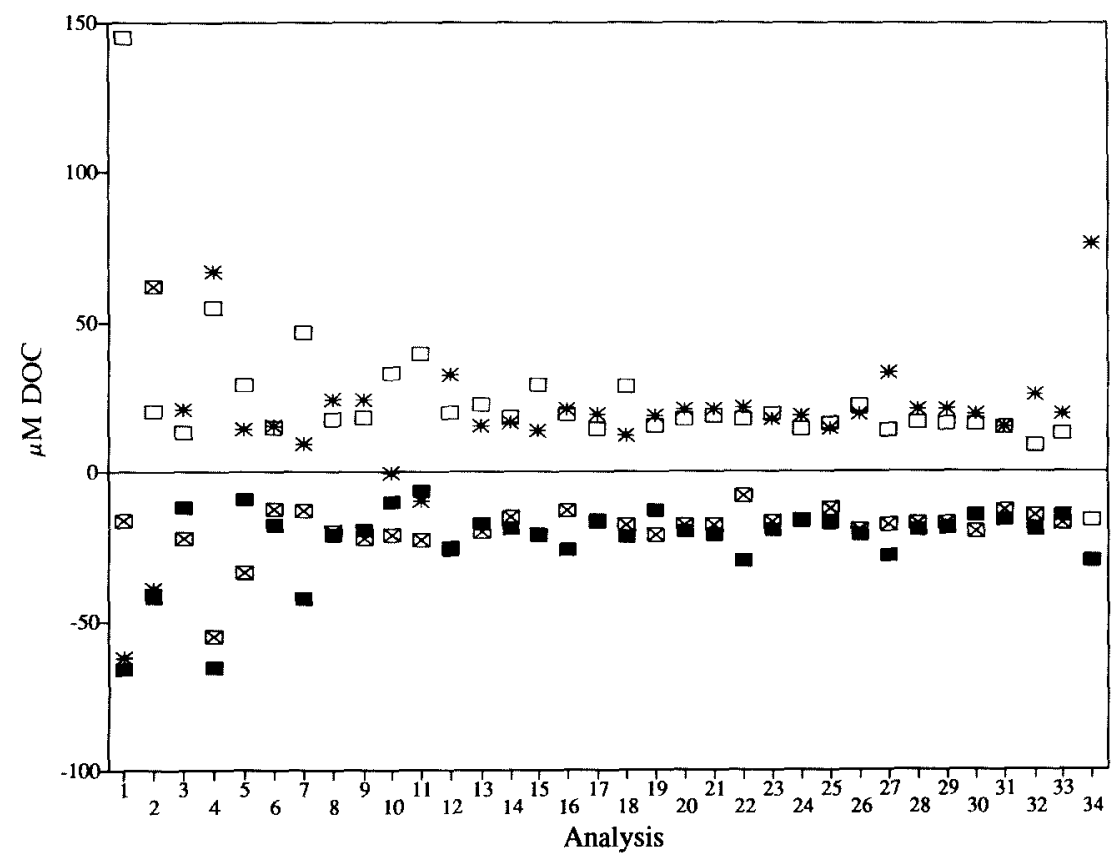

Fig. 5. DOC data for all seawater samples after mean subtraction. In this treatment the mean for every set of four measurements in a given analysis is subtracted from each individual measurement. These data are presented in the same order and format as in Figure 1. 
... the necessity for

additional

intercomparison

exercises, especially

where all analysts and

analyzers are

indentified. funded to measure DOC and DON. ${ }^{1}$ First, two or more analysts with HTCO analyzers should participate in the same cruise and measure DOC in identical samples using a common infra-red $\mathrm{CO}_{2}$ detector. Second, closed-tube combustions should be compared with HTCO injection measurements as soon as possible to assess accuracy. And third, a viable communication network should be instigated between DOC/DON analysts with respect to the rapid dissemination of analytical results, including intercomparisons.

\footnotetext{
' A Committee (J. Sharp, Chair, J. Hedges, C. Hopkinson, A. Knap and C. Lee) has been set up to resolve the measurement of DOC and DON in the sea. Its primary focus is to endorse methods and develop protocols vis-à-vis the 1992 JGOFSEQPAC cruises.

\section{Acknowledgements}

The steering committee is indebted to the hospitality of the Seattle Battelle Conference Center in hosting this Workshop and to Tracey Watkins of the University of Washington for vital logistic support. All Figures and Tables 2 to 4 are taken from Hedges et al. (see Table 1).

\section{References}

Bauer, J.E., R.I. Haddad and D.J. Des Marais. 1991: Method for determining stable isotope ratios of dissolved organic
}

carbon in interstitial and other natural waters. Mar. Chem., 33, 335-353.

P.M. Williams, E.R.M. Druffel and Y. Suzuki, 1990: Deep profiles of dissolved organic carbon in the Sargasso Sea south of Bermuda. EOS, 7I, 154.

Druffel, E.R.M., P.M. Williams and Y. Suzuki, 1989: Concentrations and radiocarbon signatures of dissolved organic carbon in the Pacific Ocean. Geophys. Res. Lett., 16, 991-994.

Jackson. G.A., 1988: Implications of high dissolved organic matter concentrations for oceanic properties and processes. Oceanography, 1, 28-33.

Maita, Y. and M. Yanada, 1990: Vertical distribution of total dissolved nitrogen and dissolved organic nitrogen in seawater. Geochemical J., 24, 245-254.

Sugimura, Y. and Y. Suzuki, 1988: A high temperature catalytic oxidation method of non-volatile dissolved organic carbon in seawater by direct injection of liquid samples. Mar. Chem., 24, 105-131.

Suzuki, Y., Y. Sugimura and T. Itoh, 1985: A catalytic method for the determination of total nitrogen dissolved in seawater. Mar. Chem., 16, 83-97.

, E. Tanone and H. Ito, 1992: High temperature catalytic oxidation method for dissolved organic carbon determination in seawater-examination and improvement. Deep-Sea Res., 39, 185-198.

Walsh, T.W., 1989: Total dissolved nitrogen in seawater: a new high-temperature combustion method and a comparison with photo-oxidation. Mar. Chem., 26, 295311

Williams, P.M. and E.R.M. Druffel, 1988: Dissolved organic matter in the ocean: comments on a controversy. Oceanography, 1, 14-17. 